\title{
Attitudes, behavior and impact of Ramadan fasting patient education in high-risk groups during Ramadan Fasting
}

Fatheya Alawadi, Maryam Al Saeed, Alaaeldin Basheir, Fauzia Rashid, Azza Khalifa, Fawzi Eltayb, Sona Abuelkheir, Mohammed Abdellatif, Fatima Sayyah, Elamin Abdelgadir, Khadija Abdulla, Mohamed Hassanein

Endocrine Department, Dubai Hospital, Dubai, UAE

\section{Background:}

- Recent studies indicates that the $94 \%$ of people with type 2 DM wish to fast, however, only $67 \%$ of them are able to fast the full month.

- Fasting may increase risk of hypoglycaemia, hyperglycaemia and/or DKA and hence advise to not fast is offered to high risk patients.

- Ramadan-focused education has previously shown to lower risk of hypoglycaemia during Ramadan. However, no previous studies have looked into the attitude, behavior and impact of Ramadan focused education in those with diabetes considered as high-risk group for Ramadan fasting.

\section{Aim \& Methods}

- We aimed to assess the attitude and behavior as well as the impact of Ramadan focused education for people with diabetes considered as very high/high risk group for fasting Ramadan.

- 170 person with type 1 diabetes, type 2 diabetes treated with insulin, people with stable CVD and diabetes, people with CKD stage 3 and diabetes as well as women with gestational diabetes were recruited to the Dubai Hospital, Diabetes and Ramadan study.

- Study was funded by a grant from Al-Jalila Foundation and approved by our local ethics committee

- All patients consented to take part in the study.

\section{Results}

The baseline characteristic are as outlined in Table 1. Average days of fasting ranged from 22.1 in GDM to 29.2 in T2D on insulin. People with CVD \& CKD were less likely to break their fast in case of hypoglycaemia.

Table 1: Baseline Characteristics

\begin{tabular}{|l|c|c|c|c|c|}
\hline DM Type \& number & $\begin{array}{c}\text { Age } \\
\text { (ys) }\end{array}$ & $\begin{array}{c}\text { Duration of } \\
\text { DM (ys) }\end{array}$ & $\begin{array}{c}\text { Average } \\
\text { Number of days } \\
\text { fasted }\end{array}$ & $\begin{array}{c}\text { \% Fasting } \\
\text { whole } \\
\text { month }\end{array}$ & $\begin{array}{c}\text { Breaking } \\
\text { fast when } \\
\text { hypo }\end{array}$ \\
\hline All $n=171$ & 47.4 & 10.6 & 27.7 & $64 \%$ & $85 \%$ \\
\hline T1D $n=30$ & 23.6 & 8.6 & 24.1 & $21 \%$ & $95 \%$ \\
\hline T2D on Insulin $n=69$ & 55 & 10.1 & 29.2 & $72 \%$ & $83 \%$ \\
\hline CKD3 $n=21$ & 62 & 14.5 & 27 & $63 \%$ & $50 \%$ \\
\hline CVD $n=25$ & 58 & 13.2 & 28 & $81 \%$ & $43 \%$ \\
\hline GDM $n=26$ & 31.3 & NR & 22.1 & $59 \%$ & $88 \%$ \\
\hline
\end{tabular}

All patients reported improved confidence in knowledge for safe fasting except for the GDM group where this reduced from presession value of $92 \%$ to post session level of $70 \%$ Chart 1 . The educational benefit of the educational session was reported at a mean value of $93 \%$ with no major difference among the groups.

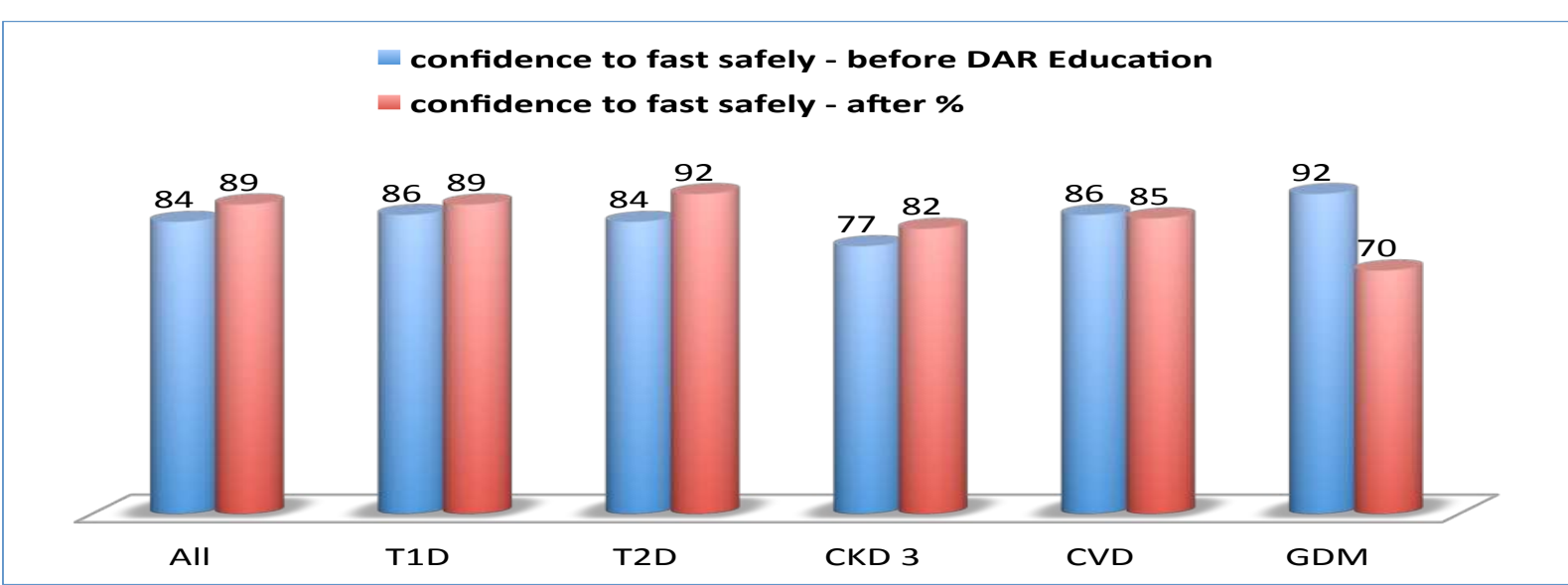

- Patients were asked about rates of hypoglycaemia before and during Ramadan (Chart 2). Rates of hypoglycaemia varied among the different groups. This was further assessed through the Freestyle Libre data and is reported in other presentations.

\section{Chart 2: Patients With Hypoglycaemia Pre and During Ramadan}

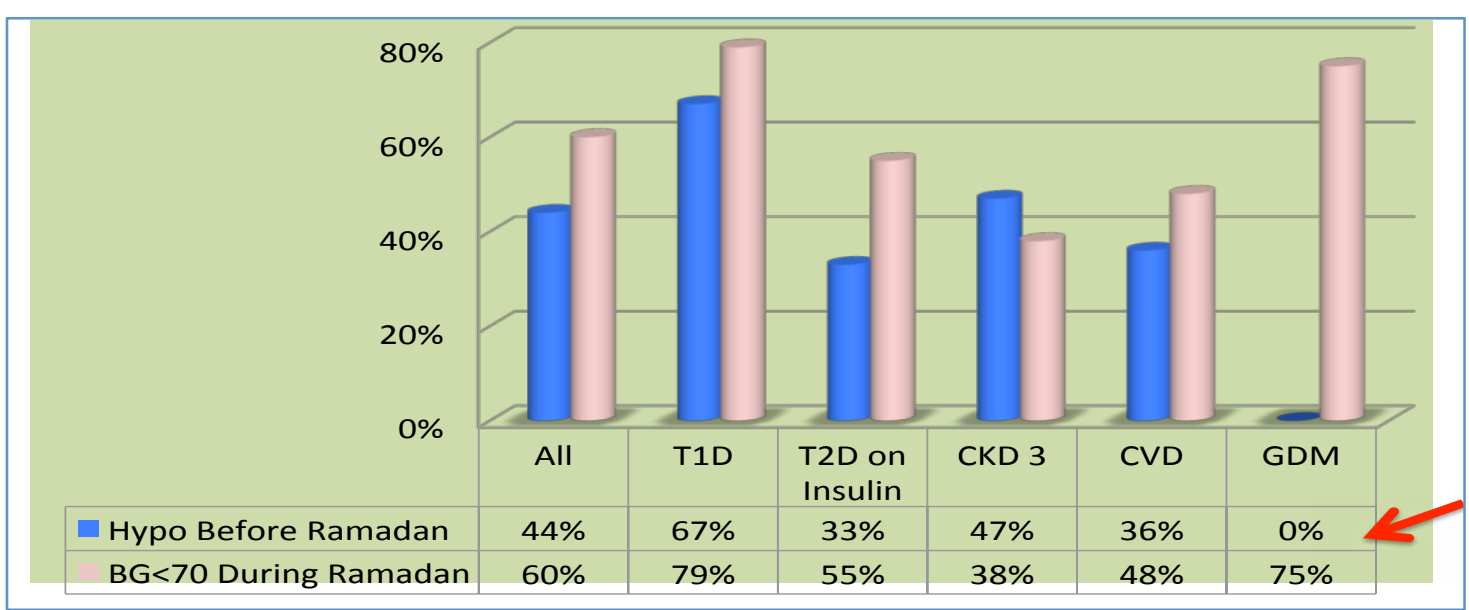

- Any change in timing, dose or type of treatment was recorded (Chart 3). Insulin treatment was adjusted in $77 \%$ of patients GDM patients were treated with diet and or metformin and hence the low rate of treatment change.

\section{Chart 3: Change in Treatment During Ramadan}

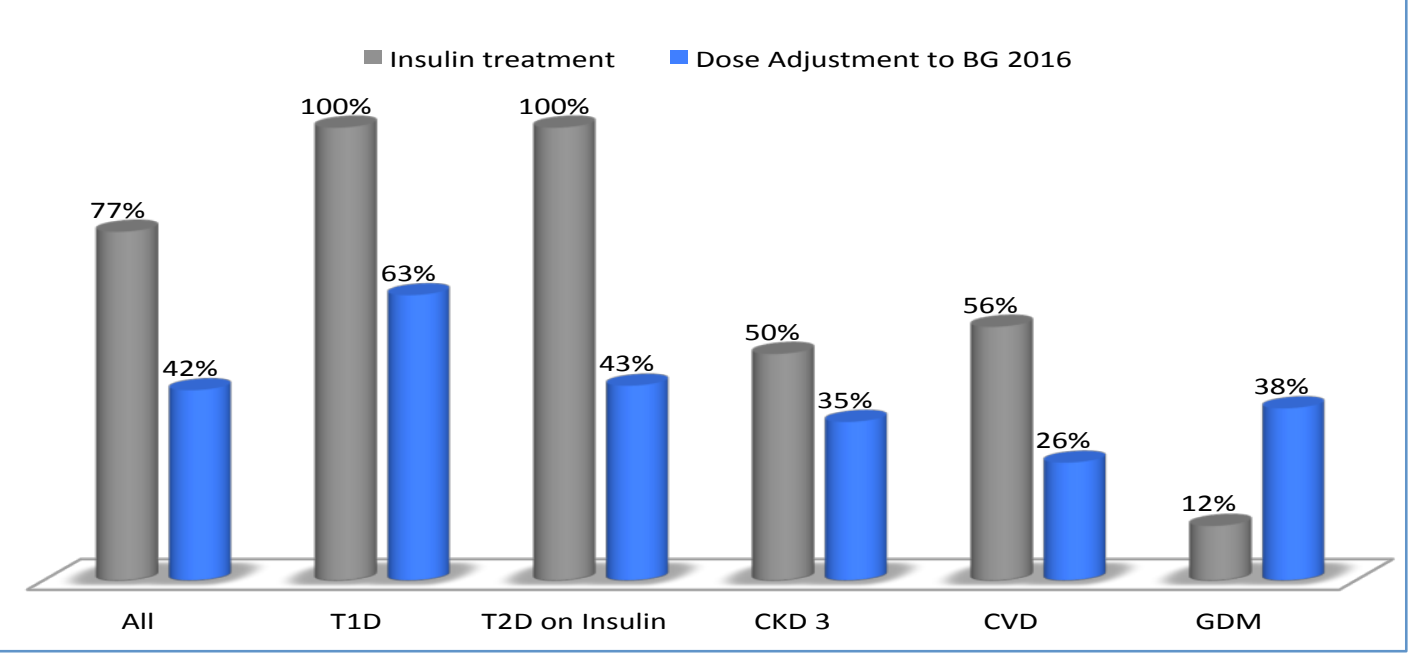

Discussion and Conclusions:

The data in this study included high risk patients patients attending specialized diabetes care, therefore, may not be generalized to other populations. Some data of questionnaire were retrospective in design which might lead to some bias.

The vast majority of our high risk patients reported educational benefit from Ramadan-focused diabetes education. The majority of our high risk patients were keen to fast and many have completed the full month fasting with average fasting days of 27.7

Treatment dose adjustment during Ramadan fasting needs further education and re-enforcement. Hospitalization for diabetes related causes in our high risk group was rare. Hypoglycemia rates increased during Ramadan and in some to a high frequent level. Breaking the fast when in hypoglycemia was well practiced by T1D and GDM patients. However, in other groups a sizeable proportion sustained fasting despite hypoglycemic BG levels on CGM data. Further research in this group is warranted

eferences:

.

Hassanein M, Al-Arouj M, Hamdy O, Bebakar WMW, Jabbar A, Al-Madani A, et al. Diabetes and Ramadan: Practical guidelines. Diabetes Research and Clinical Practice 2017;126:303-16. 16:527-536, 2014.

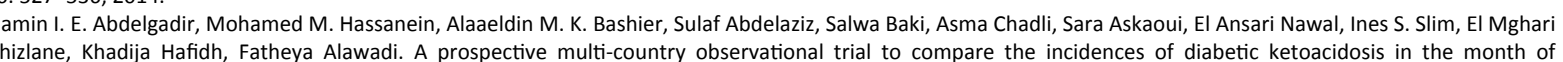

